\title{
Optimising sexually transmitted infection screening in correctional facilities: San Francisco, 2003-5
}

\section{Pennan M Barry, Charlotte K Kent, Katherine C Scott, Ameera Snell, Joseph Goldenson, Jeffrey D Klausner}

See end of article for authors' affiliations

Correspondence to: Dr Pennan M Barry, 1360 Mission Street, Suite 401, San Francisco, CA 94103 USA; pennanbarry@gmail. com

Accepted 1 June 2007

\begin{abstract}
Objectives: Sexually transmitted infection (STI) screening in correctional facilities provides access to people at high risk for STls who might not be screened elsewhere. These screening programmes are becoming more widespread, but with decreasing funding for STI control, maximising screening impact has become increasingly important. We aimed to make recommendations about the impact of age and sex targeted screening in correctional facilities.

Methods: We compared the prevalence of chlamydia and gonorrhoea for January 2003-July 2005 among different age groups of females and males screened in San Francisco correctional facilities-youth detention (12-17 years) and adult jail (18-35 years).

Results: 16975 chlamydia tests and 13443 gonorrhoea tests were performed. The age specific chlamydia test positivity among females aged 12-17 years, 18-25 years, and 26-30 years, respectively, was $9.6 \%$ (105/1092), 9.4\% (196/2088), and 6.3\% (40/639), compared with 3.3\% (100/3065), 6.2\% (400/6470), and $3.9 \%(118 / 3046)$ among males. The age specific gonorrhoea test positivity among females in these same age groups was $3.2 \%(34 / 1062), 2.7 \%(57 / 2082)$, and $2.4 \%(15 / 635)$, compared with $0.7 \%(7 /$ $1026), 1.2 \%(67 / 5507)$, and $1.0 \%(25 / 2555)$ among males. Of the 1198 STls identified, 1020 (85.1\%) were treated.

Conclusions: On the basis of this report and national data, STI control programmes with limited funds should prioritise screening females in youth detention first, women aged $\leqslant 30$ years in adult jail second, and men aged $\leqslant 25$ years in adult jail third. Males in youth detention should have a lower priority than young adults in jails.
\end{abstract}

$\mathrm{T}$ he prevalence of sexually transmitted infections (STIs) is high among people entering correctional facilities. ${ }^{1}$ Screening in correctional facilities is a viable option for STI control programmes ${ }^{2}$ and provides access to those at high risk for STIs who might not test at other venues. Because the majority of people detained in jails return to their communities within days or weeks of incarceration, ${ }^{3}{ }^{4}$ age specific STI screening and treatment of individuals entering jails or youth detention centres is likely to be an effective strategy to reduce rates of STI transmission in the community. For those reasons, the US Centers for Disease Control and Prevention (CDC) recommends voluntary chlamydia screening for females in correctional facilities. $^{5}$

In 2004, at least 34 US states had STI screening programmes in place in correctional facilities. ${ }^{6}$ Jurisdictions that have established screening programmes according to CDC recommendations for females in youth detention ${ }^{5}$ (females aged $\leqslant 18$ years) have expanded or might want to expand these programmes to include screening of males. Other programmes have expanded screening to adults in jails (generally people aged $>18$ years). Varied prevalence of STIs by age and sex alters the costs of identifying each infection, and because limited funds are available, jurisdictions might seek ways to maximise the cost effectiveness of such screening programmes. The San Francisco Department of Public Health (SFDPH) has offered voluntary chlamydia and gonorrhoea screening to people housed in youth detention and adult jail since 1997. To make recommendations about the impact of age and sex targeted screening in correctional facilities, we compared the prevalence of chlamydia and gonorrhoea among different age groups of females and males screened in San Francisco correctional facilities.

\section{METHODS}

We analysed the prevalence of chlamydia and gonorrhoea among 16960 males and females voluntarily screened in adult jails and youth detention facilities in San Francisco for January 2003-July 2005. In youth detention, females aged 12-17 years were eligible for both chlamydia and gonorrhoea screening, whereas males in this age group were eligible only for chlamydia screening. (Before 2003, the prevalence of gonorrhoea among adolescent males in detention was $<1 \%$.) However, males in youth detention were screened for gonorrhoea during 2005, after we had observed an increase in gonorrhoea among young heterosexuals in San Francisco. In adult jails, screening was offered to males aged 18-30 years and females aged 18-35 years at jail intake when an SFDPH member of staff was present (approximately 40-80 hours per week). Screening was subsequently offered to individuals in housing units not screened at intake. No criteria other than age and availability of staff were used to select people for screening. During 2004, a total of $43 \%$ of individuals eligible for screening in adult jails and $>90 \%$ of people eligible for screening in youth detention were tested for gonorrhoea or chlamydia. During 2003-4, the SFDPH laboratory tested urine for chlamydial and gonococcal DNA by using strand displacement amplification (BDProbeTec, BD, Franklin Lakes, NJ, USA) and in 2005, switched to transcription mediated amplification (Aptima Combo 2, Gen-Probe, Inc, San Diego, CA, USA). Patients for whom sex was not identified or who identified their sex as transgender were not included in this analysis ( 126 people). In

Abbreviations: CDC, Centers for Disease Control and Prevention; SFDPH, San Francisco Department of Public Health; STI, sexually transmitted infections 

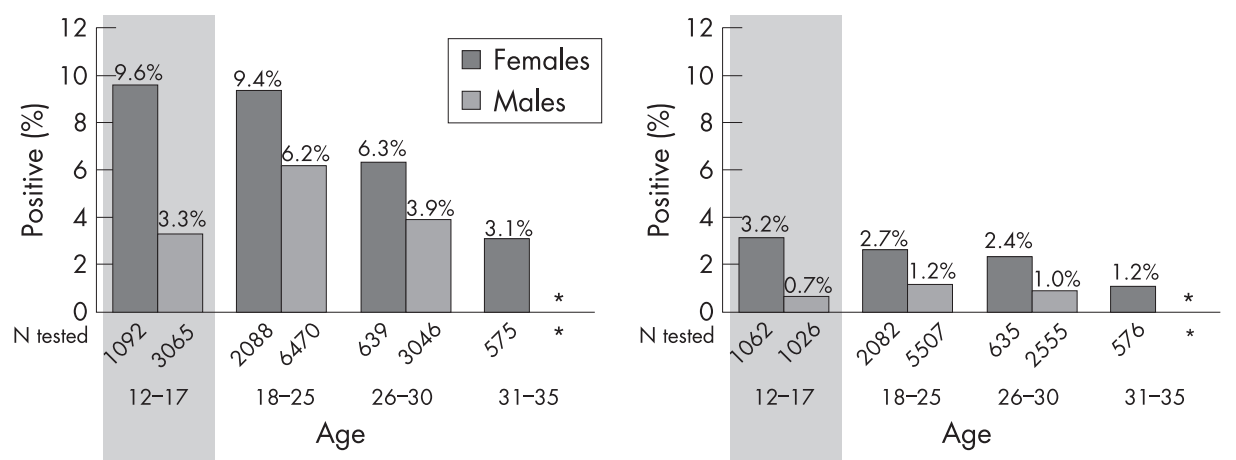

Figure 1 Chlamydia and gonorrhoea percentage positive and number positive among people screened in adult jails and youth detention centres - San Francisco, January 2003-July 2005. Shaded area indicates youth detention. *Males aged 3135 years not eligible for screening.
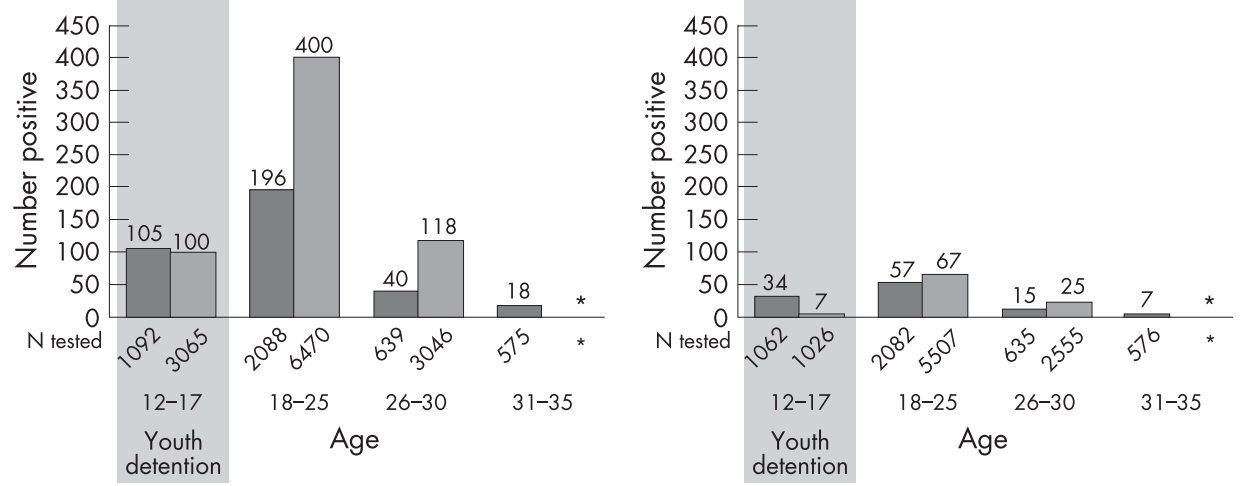

addition, we did not include unsatisfactory or indeterminate test results in the prevalence analysis (three gonorrhoea and three chlamydia tests). When possible, correctional health services staff treated people with positive tests before release. SFDPH staff attempted to locate and treat people who tested positive but were released before results became available. A CDC human subjects review determined this analysis to be a non-research public health programme evaluation; no institutional review board assessment was required.

\section{RESULTS}

During January 2003-July 2005, a total of 16975 chlamydia tests and 13443 gonorrhoea tests were performed. A total of $74 \%$ (12 581/16 975) of chlamydia testing and 68\% (9088/ 13443 ) of gonorrhoea testing was among males. This testing programme identified 359 chlamydial infections among females (8.2\% of those tested) and 618 chlamydial infections among males (4.9\% of those tested). It also identified 113 gonococcal infections among females $(2.6 \%$ of those tested) and 99 among males (1.1\% of those tested). The highest prevalence for both diseases occurred among females aged 1217 years (9.6\% for chlamydia; 3.2\% for gonorrhoea) (fig 1). However, women aged 18-25 years had approximately identical prevalence of infection as younger women, and 82\% more (253 versus 139) chlamydial and gonococcal infections were detected among women aged 18-25 years than younger women. Among males, the highest prevalence occurred among those aged 1825 years (6.2\% for chlamydia; $1.2 \%$ for gonorrhoea). The lowest prevalence among males occurred among those aged 1217 years $(3.3 \%$ for chlamydia; $0.7 \%$ for gonorrhoea). Women aged 26-30 years had an approximately equivalent prevalence of chlamydia $(p=0.92)$ but double the prevalence of gonorrhoea as men aged $18-25$ years $(p=0.07)$. Because of both the higher prevalence of infection and the greater number of men aged 18-25 years available to be screened in jail than male adolescents aged 12-17 years in youth detention, four times more chlamydial infections were detected and treated among young men in jails than among males in youth detention.

Of the 1198 STIs identified, $1020(85.1 \%)$ were treated. Among those treated, the proportion of infections treated was
$91 \%$ in youth detention and $84 \%$ in adult jail $(p=0.003)$. A total of $851(71.0 \%)$ infections were treated within 14 days of specimen collection. A total of 804 (78.8\%) infections were treated while the detainee was in jail or youth detention; 120 ( $11.8 \%$ ) were treated by SFDPH staff after the detainees' release from adult jail or youth detention; and 96 (9.4\%) were treated when the detainee was elsewhere.

\section{DISCUSSION}

On the basis of this report and national data, ${ }^{6}$ STI control programmes with limited funds should prioritise screening females in youth detention first (those aged 12-17 years), women in adult jail aged $\leqslant 30$ years second, and men in adult jail aged $\leqslant 25$ years third. Because males in youth detention have the lowest prevalence of infection, they should be a lower priority population for screening than young adults in jails. In adult jails, STI prevalence is highest among young women and men, and more infections potentially can be identified and treated among this population compared with youth detention, because of the higher prevalence of infection and the greater number of incarcerated young adults compared with adolescents.

Optimising STI screening by implementing such a focused programme might allow other jurisdictions to start or expand screening programmes in correctional facilities. Expanding screening and treatment in correctional facilities is likely to be important for overall STI control. Similar to people at high risk for STIs, people detained in correctional facilities have a history of low education, drug and alcohol abuse, and of being aged $<30$ years. ${ }^{7}$ In addition, black people and other racial or ethnic minorities are at increased risk for STIs and pelvic inflammatory disease $^{6}$ and have a high rate of incarceration. ${ }^{7}$ The US Bureau of Justice statistics demonstrate that more than $60 \%$ of detained people are in racial or ethnic minorities; $10 \%$ of black men in the United States aged 18-29 years are incarcerated; and 32\% of all black men will enter state or federal prison during their lifetime. ${ }^{7}$ Other analyses of San Francisco data (not shown) have indicated that all racial/ethnic groups of people held in youth detention and adult jails have high STI positivity so further narrowing of screening criteria by race would probably result in substantial numbers of infections being missed. 
Though this report focuses on screening in correctional facilities in the United States, screening incarcerated populations is likely to be effective at identifying large numbers of infections in many other countries as well because incarcerated people are likely to be at increased risk for STIs. In the United Kingdom, for example, a study showed that incarcerated women were at high risk for contracting STIs: $27 \%$ had a history of STI, $12 \%$ had 10 or more sex partners in the previous year, and $48 \%$ reported never using condoms. ${ }^{8}$ In fact, the United Kingdom's National Chlamydia Screening Programme, which screens men and women aged $<25$ years, includes prisons as screening sites. This programme reported $12 \%$ positivity in 2005-6 and plans to expand in the future.9

However, because overall STI control funding is limited in the United States and throughout the world, implementation of screening programmes should focus on the people at highest risk in correctional facilities. Recent data indicate that STI screening programmes in correctional facilities are often screening women who are in older age groups where STI risk is low. ${ }^{6}$ This pattern of STI screening would lower positivity rates and increase the cost per infection identified. Evidence exists that screening incarcerated older women at low risk might be widespread; published chlamydia positivity rates are higher in family planning clinics (which serve young women at lower risk) than in adult jails (which serve women at higher risk) for 11 of 20 US states reporting this information in 2003. ${ }^{10}$ If only young people (males aged $\leqslant 25$ years and females aged $\leqslant 30$ years) were screened in jails, only approximately $30 \%$ of the incarcerated population would be screened, ${ }^{7}$ requiring a dramatically reduced expenditure of resources.

The findings in this report are subject to limitations. Firstly, although $>90 \%$ of adolescents in youth detention were screened, only $40 \%$ of young adults in jail were screened. No differential selection criteria were used for who was screened at either type of facility. This difference in screening coverage was the result of limited staff available to offer screening in adult jail. Thus, the substantially greater number of infections identified and treated among jail detainees than youth detention might be even greater if we had the resources to screen $90 \%$ of young adults in jail. Secondly, San Francisco has moderate rates of gonorrhoea and chlamydia among heterosexuals (San Francisco ranks 53rd for chlamydia and 58th for gonorrhoea among women in 63 selected US cities ${ }^{6}$ ); therefore, the prevalence of infection by age and sex of people in detention identified in San Francisco will not be generalisable to all jurisdictions. However, the age distribution of STI prevalence observed in San Francisco is similar to other jurisdictions with screening programmes in correctional facilities. ${ }^{6}$ Jurisdictions with higher overall morbidity report higher prevalence of infection among males and females in youth detention than in San Francisco. ${ }^{6}$ However, if these jurisdictions began screening young adults in jails, they might find a higher prevalence of infection among males and more infections to treat among both males and females than is reported in youth detention.

STI control programmes should consider focused chlamydia and gonorrhoea screening and treatment of young adults in jails (males aged $\leqslant 25$ years and females aged $\leqslant 30$ years) and, depending upon the prevalence of infection, limit the screening of males in youth detention. Further studies on the impact of screening in correctional facilities on community STI rates are needed.

\section{ACKNOWLEDGEMENTS}

This report is based, in part, on data contributed by Ericka Enright and Cynthia Horton, San Francisco Department of Public Health, San Francisco Jail Health Services staff, and San Francisco Youth Guidance Center staff. Presented in part at the 2005 International Society of Sexually Transmitted Disease Research Conference, Amsterdam.

\section{Key messages}

- This analysis of the voluntary STI screening programme in San Francisco correctional facilities (youth detention for people aged less than 18 years and adult jails for people aged more than 18 years) demonstrated varying test positivity rates by age and sex

- On the basis of this report and national data, STI control programmes with limited funds should prioritise screening females in youth detention first, women in adult jail aged $\leqslant 30$ years second, and men in adult jail aged $\leqslant 25$ years third

- Because males in youth detention have the lowest prevalence of infection, they should be a lower priority population for screening than young adults in jails.

Contributors: PB conducted all analysis and led the writing; CK conceived and supervised all aspects of the study; KS assisted with the conception of the study and with data analysis; KS, AS, and JG assisted with and supervised the jail screening programme; JK supervised all aspects of the study. All authors helped to interpret findings and review drafts of the manuscript.

\section{Authors' affiliations}

Pennan M Barry, Epidemic Intelligence Service, Office of Workforce and Career Development, Centers for Disease Control and Prevention, Atlanta, GA, USA

Pennan M Barry, Charlotte K Kent, Katherine C Scott, Ameera Snell, Joseph Goldenson, Jeffrey D Klausner, San Francisco Department of Public Health, San Francisco, CA, USA

Disclaimer: The findings and conclusions in this report are those of the author(s) and do not necessarily represent the views of the Centers for Disease Control and Prevention.

Copyright statement: This article was prepared by an employee of the Federal Government as part of official duties and is, under the Copyrights Act, a "work of the United States Government" for which copyright protection under Title 17 of the United States Code is not available.

\section{REFERENCES}

1 Cohen DA, Kanouse DE, Iguchi MY, et al. Screening for sexually transmitted diseases in non-traditional settings: a personal view. Int J STD AIDS 2005; 16:521-7.

2 Mertz KJ, Voigt RA, Hutchins K, et al. Findings from STD screening of adolescents and adults entering corrections facilities: implications for STD control strategies. Sex Transm Dis 2002;29:834-9.

3 Cohen D, Scribner R, Clark J, et al. The potential role of custody facilities in controlling sexually transmitted diseases. Am J Public Health 1992;82:552-6.

4 Centers for Disease Control and Prevention. Assessment of sexually transmitted diseases services in city and county jails-United States, 1997. MMWR Morb Mortal Wkly Rep 1998;47:429-31.

5 Centers for Disease Control and Prevention. Recommendations for the prevention and management of Chlamydia trachomatis infections, 1993. MMWR Recomm Rep 1993;42(No RR-12): 1-39.

6 Centers for Disease Control, Prevention (CDC). Sexually transmitted disease surveillance, 2004. 2005. Atlanta, GA: US Department of Health and Human Services, CDC, 2005.

7 Bureau of Justice Statistics. Criminal offenders statistics. Washington, DC: US Department of Justice, 2005, Available at http://www.ojp.usdoj.gov/bjs/ crimoff.htm, accessed 25 August, 2005.

8 Plugge E, Douglas N, Fitzpatrick R. The health of women in prison study findings. Oxford: Department of Public Health, University of Oxford, 2006, Available at:http://www.publichealth.ox.ac.uk/units/prison/2007-02-13.6702780065/ download.

9 National Chlamydia Screening Steering Group. New frontiers: annual report of the National Chlamydia Screening Programme in England 2005/06. London: Health Protection Agency, November 2006, Available at:www.dh.gov.uk/ PolicyAndGuidance/HealthAndSocialCareTopics/SexualHealth/ SexualHealthGenerallnformation/SexualHealthGeneralArticle/fs/ en?CONTENT_ID $=4084098 \&$ chk = CSLxsK.

10 Centers for Disease Control and Prevention. Sexually transmitted disease surveillance 2003 Supplement, Chlamydia Prevalence Monitoring Project. 2004. Atlanta, GA: US Department of Health and Human Services, CDC, 2004. 